Models for Truncated Counts

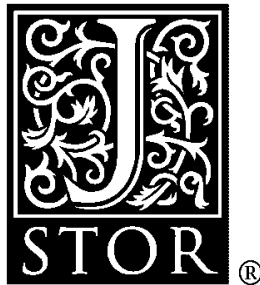

\author{
J. T. Grogger; R. T. Carson
}

Journal of Applied Econometrics, Vol. 6, No. 3. (Jul. - Sep., 1991), pp. 225-238.

Stable URL:

http://links.jstor.org/sici?sici=0883-7252\%28199107\%2F09\%296\%3A3\%3C225\%3AMFTC\%3E2.0.CO\%3B2-N

Journal of Applied Econometrics is currently published by John Wiley \& Sons.

Your use of the JSTOR archive indicates your acceptance of JSTOR's Terms and Conditions of Use, available at

http://www.jstor.org/about/terms.html. JSTOR's Terms and Conditions of Use provides, in part, that unless you have obtained prior permission, you may not download an entire issue of a journal or multiple copies of articles, and you may use content in the JSTOR archive only for your personal, non-commercial use.

Please contact the publisher regarding any further use of this work. Publisher contact information may be obtained at http://www.jstor.org/journals/jwiley.html.

Each copy of any part of a JSTOR transmission must contain the same copyright notice that appears on the screen or printed page of such transmission.

The JSTOR Archive is a trusted digital repository providing for long-term preservation and access to leading academic journals and scholarly literature from around the world. The Archive is supported by libraries, scholarly societies, publishers, and foundations. It is an initiative of JSTOR, a not-for-profit organization with a mission to help the scholarly community take advantage of advances in technology. For more information regarding JSTOR, please contact support@ jstor.org. 


\title{
MODELS FOR TRUNCATED COUNTS
}

\author{
J. T. GROGGER \\ Department of Economics, University of California, Santa Barbara, Santa Barbara, CA 93106, USA \\ AND \\ R. T. CARSON \\ Department of Economics, University of California, San Diego, La Jolla, CA 92093, USA
}

\begin{abstract}
SUMMARY
This paper examines a class of maximum-likelihood regression estimators for count data from truncated samples. Estimators for the truncated Poisson and negative binomial distributions are illustrated. Simulation results are given to illustrate the magnitude of the bias that may result from the failure to account for overdispersion in truncated samples. An empirical application based upon the number of recreational fishing trips taken by a sample of Alaskan fishermen is provided.
\end{abstract}

\section{INTRODUCTION}

The estimation and application of count regression models is receiving much attention from econometricians. (Gourieroux, Monfort, and Trognon, 1984b; Hausman, Hall, and Griliches, 1984; Lee, 1986). These models have seen increasing use in the analysis of outcomes naturally measured as non-negative integers; applications include studies of firms' patenting behaviour (Hausman, Hall, and Griliches, 1984), doctor and hospital visits (Cameron and Trivedi, 1986; Cameron et al., 1988), daily beverage consumption (Mullahy, 1986), incidents of pollutioninduced illness (Portney and Mullahy, 1986), and daily homicide counts (Grogger, 1990).

In many cases, however, the analyst does not observe the entire distribution of counts. In particular the zeros often are not observed. Consider an example of such a situation. A public transit authority sends out interviewers to administer surveys on different buses asking about the number of bus trips taken per week and other variables which might be related to that behaviour, such as attitudinal and demographic variables. Given these data we seek to construct a model of the number of weekly bus trips taken as a function of various exogenous variables, some of which are under the control of the public transit authority. Due to the choice-based sampling scheme employed, no observations are made of individuals making zero bus trips, since a criterion for sample inclusion is that at least one bus trip be made. The dependent variable in our model, the number of bus trips taken that week, is truncated at zero, taking on only positive values.

More generally, two common types of sampling schemes are likely to give rise to samples of truncated counts: surveys which ask 'participants' about the number of 'participation occasions' and samples drawn from administrative records where inclusion in such a database is predicated on having engaged in the activity of interest. Examples of the first type include on-site sampling plans, surveys of owners of a particular home appliance (e.g. from warranty 
cards or catalogue purchase records) about use patterns and surveys of individuals in mall intercept marketing surveys about number of shopping trips. Data sets of the second type are common in work on employment, health, and crime. The underlying statistical similarity between both types of samples is that the observational apparatus potentially becomes active only with the occurrence of some specified (typically one) number of events (Johnson and Kotz, 1969).

Recently, Shaw (1988) has proposed normal and Poisson regression models for the analysis of truncated samples of count data. In this paper we extend the analysis of Shaw in several directions. In Section 2 we introduce some notation and two count regression models for nontruncated samples. In Section 3 we propose estimators based on the truncated negative binomial distribution as well as the Poisson. The choice of models is shown to be important in analyzing truncated samples: application of the truncated Poisson model to data which fail to meet its stringent moment restrictions may result in seriously biased and inconsistent parameter estimates. In Section 4 we provide an interpretation for the parameters and other statistics estimated from these models. The fifth section contains a small Monte-Carlo experiment which examines the finite sample properties of the estimators. In Section 6 we give an empirical example based on the prediction of the number of recreational fishing trips taken in Alaska. Section 7 contains some concluding remarks.

\section{STANDARD COUNT DATA ESTIMATORS}

A number of discrete probability distributions satisfy our requirement of generating nonnegative integers. The simplest one is the one-parameter Poisson distribution. Since many other possible count data distributions represent generalizations of the Poisson, we take it up first.

The basic Poisson model can be written as

$$
\operatorname{Pr}\left(Y_{i}=j\right)=F_{P}(j)=\frac{\exp (-\lambda) \lambda^{j}}{j !}
$$

where there are $i=1,2, \ldots, n$ observations, $Y_{i}$ is the $i$ th observation on the count variable of interest, $j=0,1,2, \ldots$ are the possible values of $Y_{i}$ (i.e. the set of nonnegative integers), and $\lambda$ is the Poisson parameter to be estimated. This model can be extended to a regression setting most easily by allowing for different $\lambda_{i}$ which vary according to

$$
\lambda_{i}=\exp \left(X_{i} \beta\right)
$$

which extends (1) to the regression case where $X_{i}$ is a 1 by $h$ vector of observed covariates and $\beta$ is an $h$ by 1 vector of unknown parameters to be estimated. The exponential specification is used to restrict $\lambda_{i}$ to be positive as is required for a proper distribution.

The log-likelihood of this model,

$$
\ln L=\sum_{i=1}^{n}-\exp \left(X_{i} \beta\right)+Y_{i} X_{i} \beta-\ln Y_{i} !,
$$

is globally concave. The conditional mean of $Y_{i}$ is given by:

$$
E\left(Y_{i} \mid X_{i}\right)=\lambda_{i}=\exp \left(X_{i} \beta\right) .
$$

We see that the exponential regression function serves to constrain predicted values to be positive. Furthermore, the coefficients can be interpreted as average proportionate changes in 
$E\left(Y_{i} \mid X_{i}\right)$ for a unit change in $X_{i}$, since

$$
\frac{\partial E\left(Y_{i} \mid X_{i}\right)}{\partial X_{i h}}=\beta_{h} E\left(Y_{i} \mid X_{i}\right)
$$

Elasticities evaluated at the data means therefore take the particularly simple form of $\varepsilon_{Y \mid \bar{X}_{h}}=\beta_{h} \bar{X}_{h}$.

Another property of this model is that the conditional variance equals the conditional mean. This mean-variance equality has proven problematic in applied work since real data frequently exhibit 'overdispersion'; that is, conditional variation greater than the mean. The conditional mean is consistently estimated using the Poisson model in the presence of overdispersion (Gourieroux, Monfort, and Trognon, 1984b), but the standard errors of $\beta$ are biased downward (Cameron and Trivedi, 1986). ${ }^{1}$ Several specification tests for overdispersion in the Poisson regression model have been proposed (Hausman, Hall, and Griliches, 1984; Lee, 1986; Grogger, 1987).

The generalization of the Poisson distribution which is often used to model such overdispersed counts is the negative binomial probability distribution (Johnson and Kotz, 1969; Hausman, Hall and Griliches, 1984; Cameron and Trivedi, 1986). This probability distribution can be written as:

$$
\operatorname{Pr}\left(Y_{i}=j\right)=F_{N B}(j)=\frac{\Gamma\left(j+\frac{1}{\alpha}\right)}{\Gamma(j+1) \Gamma\left(\frac{1}{\alpha}\right)}\left(\alpha \lambda_{i}\right)^{j}\left[1+\alpha \lambda_{i}\right]^{-(j+1 / \alpha)},
$$

where $\alpha>0$ is a nuisance parameter to be estimated along with $\beta$. The negative binomial can be derived from a Poisson distribution in which the $\lambda_{i}$ are distributed as a gamma random variable. ${ }^{2}$ The first two moments of the negative binomial distribution are given by

and

$$
E\left(Y_{i} \mid X_{i}\right)=\lambda_{i} \equiv \exp \left(X_{i} \beta\right)
$$

$$
\operatorname{var}\left(Y_{i} \mid X_{i}\right)=\lambda_{i}\left(1+\alpha \lambda_{i}\right)
$$

so that $\operatorname{var}\left(Y_{i} \mid X_{i}\right)$ is greater than $E\left(Y_{i} \mid X_{i}\right)$.

Both the Poisson and negative binomial (for given $\alpha>0$ ) distributions are members of the linear exponential family of distributions. Quasi-maximum-likelihood methods will therefore generally provide consistent estimates of the correctly specified conditional mean (Wedderburn, 1974; McCullagh, 1983; Gourieroux, Monfort, and Trognon, 1984a) when applied to a random sample from the entire underlying population of interest.

\section{TRUNCATED COUNT DATA ESTIMATORS}

The common statistical structure of truncated estimators follows from the fundamental probability relationship

$$
\operatorname{Prob}(A \mid B)=\frac{\operatorname{Prob}(A \cap B)}{\operatorname{Prob}(B)}
$$

\footnotetext{
${ }^{1}$ While White's covariance matrix estimator should provide consistent estimates of the standard errors, our experience suggests that these estimates are still smaller than those obtained from a model which directly accounts for overdispersion such as the negative binomial.

${ }^{2}$ For this reason the negative binomial is sometimes referred to a compound distribution. Other distributions for the $\lambda_{i}$ are possible but more difficult to estimate (Hinde, 1982).
} 
In our case, the expression $\operatorname{Prob}(A \cap B)$ represents the probability of observing some $Y_{i}$ while $\operatorname{Prob}(B)$ represents the probability of being at or above the truncation limit. The term $\operatorname{Prob}(A \mid B)$ represents the probability of observing $Y_{i}$, given that it exceeds the truncation point. In terms of probability distribution functions, (8) can be written as

$$
f_{k}\left(Y_{i}\right)=\frac{f\left(Y_{i}\right)}{1-F(k)}
$$

where $f_{k}\left(Y_{i}\right)$ is the truncated (above $k$ ) probability function, $f\left(Y_{i}\right)$ is the probability function, and $F(k)$ is the distribution function evaluated at $k$. To derive the maximum-likelihood estimator, a suitable discrete probability function is applied with the relationship for conditional probabilities given in (9). We now do this for the Poisson and negative binomial models presented in the previous section, concentrating on the case of $k=0$, since this is the case most likely to be encountered in practice.

For the Poisson probability function, a model for counts truncated on the left at the value $k=0$ can be posited as

$$
\operatorname{Pr}\left(Y_{i}=j \mid Y_{i}>0\right)=\frac{\exp \left(-\lambda_{i}\right) \lambda_{i}^{j}}{j !}\left[1-F_{P}(0)\right]^{-1}=\frac{\lambda_{i}^{j}}{\left(\exp \left(\lambda_{i}\right)-1\right) j !},
$$

where $j$ now takes only positive integer values larger than 0 .

The truncated probability function differs from the standard probability function by the factor $\left[1-F_{P}(0)\right]^{-1}$. Since $F_{P}(0)<1$, multiplication of the standard probabilities by $\left[1-F_{P}(0)\right]^{-1}$ inflates them, accounting for the unobserved zeros.

The log-likelihood for this model can be written as

$$
\ln L=\sum_{i=1}^{m} Y_{i} X_{i} \beta-\ln \left[\exp \left(\lambda_{i}\right)-1\right]-\ln \left(Y_{i} !\right)
$$

where $m$ is the number of observations in the truncated sample.

Newton's method can be used to find consistent maximum-likelihood estimates of $\beta .^{3}$ It can be shown that the maximum-likelihood estimator is consistent when the true data-generating process is Poisson. The parameter estimates for standard, untruncated Poisson are inconsistent, however, when applied to a sample of truncated counts since the conditional mean of the truncated dependent variable is now also dependent on $F(\cdot)$. This case is analogous to that in which OLS yields inconsistent estimates in the presence of truncation while the truncated variant of the Tobit estimator is consistent if the error terms are normal.

The conditional mean and variance of $Y_{i}$ are given by ${ }^{4}$

$$
E\left(Y_{i} \mid X_{i}, Y_{i}>0\right)=\lambda_{i}\left[1-F_{P}(0)\right]^{-1}
$$

${ }^{3}$ The first partial derivatives with respect to $\beta$ are

$$
\frac{\partial \ln L}{\partial \beta_{h}}=\sum_{i=1}^{m} X_{i t}\left[Y_{i}-\frac{\lambda_{i}}{1-\exp \left(-\lambda_{i}\right)}\right]
$$

and the second partials are given by

$$
\frac{\partial^{2} \ln L}{\partial \beta_{h} \partial \beta_{h^{\prime}}}=-\sum_{i=1}^{m} \lambda_{i} X_{i h} X_{i h^{\prime}}\left[\frac{1-\left(1+\lambda_{i}\right) \exp \left(-\lambda_{i}\right)}{\left[1-\exp \left(-\lambda_{i}\right)\right]^{2}}\right] .
$$

Since the initial draft of this paper was written, the software package GAUSS has implemented the estimators discussed here (Aptech Systems, 1989). The program LIMDEP now also provides algorithms for fitting truncated count models (Greene, 1990).

${ }^{4}$ We thank a referee for point out an error in equations (13) and (17) in an earlier draft. 
and

$$
\operatorname{var}\left(Y_{i} \mid X_{i}, Y_{i}>0\right)=E\left(Y_{i} \mid X_{i}, Y_{i}>0\right)\left[1-F_{P}(0) E\left(Y_{i} \mid X_{i}>0\right)\right] .
$$

In the case of the untruncated Poisson, $\beta$ is consistently estimated even in the presence of overdispersion, although the standard errors are downwardly biased. However, the estimates of the regression parameters and choice probabilities from a truncated Poisson model will be biased and inconsistent in the presence of overdispersion because the proper specification of the conditional mean of the truncated dependent variable, given in (12), which is necessary for consistency of the estimated $\beta$, requires the proper specification of all the moments of the underlying relevant cumulative distribution $F(\cdot)$. This finding is similar to the result that the Tobit estimator, unlike ordinary least-squares, yields inconsistent parameter estimates in the presence of heteroscedasticity.

Given the importance of accounting for overdispersion in the truncated count context, we present a model for truncated counts based on the negative binomial distribution. This negative binomial probability model can be written as

$$
\operatorname{Pr}\left(Y_{i}=j \mid Y_{i}>0\right)=\frac{\Gamma\left(j+\frac{1}{\alpha}\right)}{\Gamma(j+1) \Gamma\left(\frac{1}{\alpha}\right)}\left(\alpha \lambda_{i}\right)^{j}\left[1+\alpha \lambda_{i}\right]^{-(j+1 / \alpha)}\left[1-F_{N B}(0)\right]^{-1}
$$

The log-likelihood is

$$
\begin{aligned}
\ln L=\sum_{i=1}^{m} \ln \left(\Gamma\left(j+\frac{1}{\alpha}\right)\right)-\ln (\Gamma(j+1))- & \ln \left(\Gamma\left(\frac{1}{\alpha}\right)\right)+j \ln (\alpha)+j X_{i} \beta \\
& -\left(j+\frac{1}{\alpha}\right) \ln \left[1+\alpha \lambda_{i}\right]-\ln \left[1-\left(1+\alpha \lambda_{i}\right)^{-1 / \alpha}\right] .^{5}
\end{aligned}
$$

The conditional mean and variance of this model are given by

$$
E\left(Y_{i} \mid X_{i}, Y_{i}>0\right)=\lambda_{i}\left[1-F_{N B}(0)\right]^{-1},
$$

and

$$
\operatorname{var}\left(Y_{i} \mid X_{i}, Y_{i}>0\right)=\frac{E\left(Y_{i} \mid X_{i}, Y_{i}>0\right)}{F_{N B}(0)^{\alpha}}\left\{1-\left[F_{N B}(0)\right]^{1+\alpha} E\left(Y_{i} \mid X_{i}, Y_{i}>0\right)\right\}
$$

\section{INTERPRETATION OF MODEL RESULTS}

As in other regression settings, interest often attaches not only to the regression parameters themselves, but also to the partial derivatives and elasticities of the conditional expectation of the dependent variable with respect to the explanatory variables. In the truncated dependent variable case, one might also wish to know how both the typical member of the observable

\footnotetext{
${ }^{5}$ The first and second partial derivatives of (15) with respect to $\beta$ are given by:

and

$$
\frac{\partial \ln L}{\partial \beta_{h}}=\sum_{i=1}^{m} X_{i h}\left\{\frac{Y_{i}-\lambda_{i}}{\left(1+\alpha \lambda_{i}\right)}-\frac{\lambda_{i}\left(1+\alpha \lambda_{i}\right)^{-(1+1 / \alpha)}}{1-\left(1+\alpha \lambda_{i}\right)^{-1 / \alpha}}\right\}
$$

$$
\frac{\partial^{2} \ln L}{\partial \beta_{h} \partial \beta_{h^{\prime}}}=-\sum_{i=1}^{m} \lambda_{i} X_{i h} X_{i h^{\prime}}\left\{\frac{1+\alpha Y_{i}}{\left(1+\alpha \lambda_{i}\right)^{2}}-\frac{\lambda_{i}\left(1+\alpha \lambda_{i}\right)^{-2(1+1 / \alpha)}}{\left[1-\left(1+\alpha \lambda_{i}\right)^{-1 / \alpha}\right]^{2}}+\frac{\left(1+\alpha \lambda_{i}\right)^{-(1+1 / \alpha)}-\lambda_{i}(1+\alpha)\left(1+\alpha \lambda_{i}\right)^{(-2+1 / \alpha)}}{1-\left(1+\alpha \lambda_{i}\right)^{-1 / \alpha}}\right\} .
$$
}


population (that is, the group in the population of interest above the truncation limit, or choice threshold, from which the choice-based sample is drawn) and the typical member of the entire population of interest would change in response to a given change in an explanatory variable. We present expressions for both these magnitudes. In addition, we provide a decomposition of these derivatives into that proportion resulting from a change among those currently in the observable population, and the proportion of the change resulting from the movement of those from the unobservable category into the observable group, or vice-versa.

The expectation of $Y_{i}$ in the population of interest can be expressed in terms of the observable proportion of the population:

$$
E\left(Y_{i} \mid X_{i}\right) \equiv E\left(Y_{i} \mid X_{i}, Y_{i}>0\right)[1-F(0)] .
$$

From this equation one can obtain the unconditional derivative of $Y_{i}$ with respect to $X_{i h}$ :

$$
\frac{\partial E\left(Y_{i} \mid X_{i}\right)}{\partial X_{i h}}=\frac{\partial}{\partial X_{i}}\left[E\left(Y_{i} \mid X_{i}, Y_{i}>0\right)\right][1-F(0)]+E\left(Y_{i} \mid X_{i}, Y_{i}>0\right) \frac{\partial}{\partial X_{i h}}[1-F(0)]
$$

where

$$
\frac{\partial E\left(Y_{i} \mid X_{i}, Y_{i}>0\right)}{\partial X_{i h}}=\beta_{h} \lambda_{i}\left\{\frac{1-F_{P}(0)\left(1-\lambda_{i}\right)}{\left[1-F_{P}(0)\right]^{2}}\right\}
$$

for the Poisson model, whereas

$$
\frac{\partial E\left(Y_{i} \mid X_{i}, Y_{i}>0\right)}{\partial X_{i h}}=\beta_{h} \lambda_{i}\left\{\frac{1-F_{N B}(0)\left[1-\lambda_{i} F_{N B}(0)^{\alpha}\right]}{\left[1-F_{N B}(0)\right]^{2}}\right\}
$$

for the negative binomial model and $(\partial[1-F(0)]) / \partial X_{i h}$ equals $\beta_{h} \lambda_{i} F_{P}(0)$ for the Poisson model and $\beta_{h} \lambda_{i} F_{N B}(0)^{(1+\alpha)}$ for the negative binomial model.

From equation (19), then, we see that the effect of a change in one of the $X_{i h}$ on the latent dependent variable in the full underlying population can be inferred from information obtained from a choice-based sample. Furthermore, following McDonald and Moffitt (1980), equation (19) also indicates that this change in $Y_{i}$ can be decomposed into two effects: the change in the expected value of those above the limit, weighted by the probability of being above the limit, plus the change in the proportion of those above the limit, weighted by the dependent variable mean of those above the limit. The total effect on the underlying population of interest can thus be broken down into the effect on those already above the choice threshold and the effect of inducing those below that threshold to cross it in response to the change.

\section{SIMULATION RESULTS}

In this section we present a summary of several Monte-Carlo simulations designed to quantify for illustrative parameter values the inconsistencies which may result from application of the truncated Poisson model to overdispersed truncated samples. As before, attention is restricted to the case of truncation of the zero class, since this is the case most likely to arise in practice.

The simulations were conducted as follows. First, 500 observations on three explanatory variables were generated. These variables included a constant term, $X_{0}$, and two other regressors, $X_{1}$ and $X_{2}$, generated from a zero-mean, unit variance bivariate normal distribution with correlation $0 \cdot 20$. For each observation, $\lambda_{i}=\exp \left(X_{i} \beta\right)$ was calculated, where $\beta_{1}=\beta_{2}=0.8$ for all experiments, and the three values of $\beta_{0}$ were chosen to achieve values of $E\left(\lambda_{i}\right)$ equal to 1,3 , and 5 . Four values of $\alpha, 0 \cdot 2,0 \cdot 4,0 \cdot 6,0 \cdot 8$, were used to generate data 


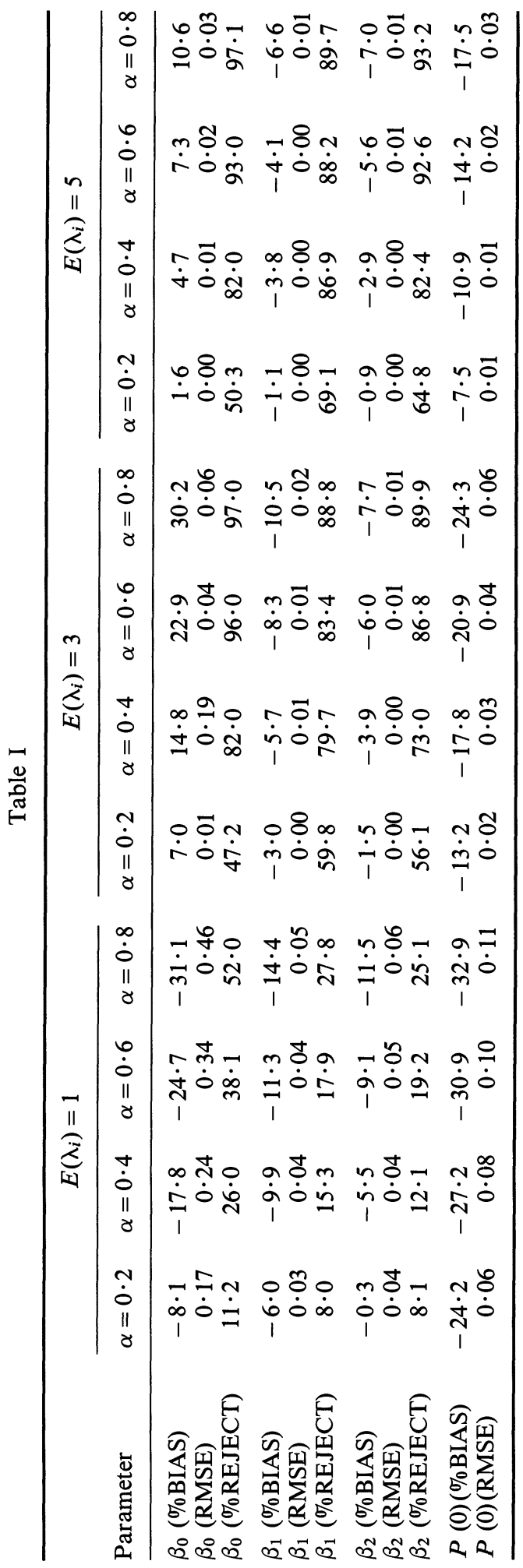


from a negative binomial distribution; higher values of $\alpha$ imply greater overdispersion. The IMSL routine RNNBN was used to generate the negative binomial variates. Observations for which $y_{i}=0$ were dropped from the estimation sample to effect the truncation; regression parameters and $P(0)$, the proportion of zero counts, were then estimated by maximizing the truncated Poisson likelihood. For each value of $\left[E\left(\lambda_{i}\right), \alpha\right], 100$ repetitions of this procedure were conducted, providing results that should be considered illustrative rather than necessarily definitive.

Table I presents the results of the experiments. For each of the regression coefficients and the proportion of zeros, $P(0)$, the estimated bias in percentage terms, and the root mean square error are reported. Also reported is the number of times out of 100 the hypothesis $\mathrm{H}_{0}: \beta_{i}=$ true value is rejected at the 95 per cent confidence level.

Table I shows that the bias resulting from the application of the truncated likelihood Poisson estimator to overdispersed samples can be substantial. For $E\left(\lambda_{i}=1\right)$, overdispersion corresponding to $\alpha=0.4$ or greater is sufficient to impart roughly 20 per cent bias in the estimate of the constant term. The effect on the estimates of $\beta_{1}$ and $\beta_{2}$ is substantial as well, on the order of 10 per cent. The magnitude of the inconsistency increases in $\alpha$, and the frequency with which the 95 per cent confidence interval associated with the truncated Poisson parameter estimates excludes the true value.

In general one sees that, as $E\left(\lambda_{i}\right)$ increases, the magnitude of the inconsistency problem is reduced. For $E\left(\lambda_{i}\right)=3$, regression parameters are estimated with 2-10 per cent bias on average for various values of $\alpha$, and bias in the zero frequency estimates is reduced by a factor of two to three. This result is to be expected, since higher values of $E\left(\lambda_{i}\right)$ are associated with fewer zeros in the population for any given $\alpha$. The bias in the parameter estimates is directly related to the size of the bias in the estimate of $P(0)$. Note though that even for $E\left(\lambda_{i}\right)=5$, overdispersion of magnitude $\alpha>0.6$ or greater results in bias on the order of 5 per cent. Failure to take account of $\alpha>0$ has a much more dramatic effect on rejection probabilities. These rejection frequencies increase away from the desired 5 per cent level as $\alpha$ and $E\left(\lambda_{i}\right)$ increase, rising as high as 97 per cent.

We have also conducted simulations applying the standard Poisson and negative binomial models and the truncated negative binomial model to data generated from a truncated negative binomial distribution. These results are available from the authors. They show, as one might expect, that the truncated negative binomial is essentially unbiased. The standard Poisson model, on the other hand, can have biases over 100 per cent for small values of $E\left(\lambda_{i}\right)$, particularly for large values of $\alpha$. The 95 per cent confidence intervals from standard Poisson model estimates rarely contain the true parameter values in this situation. The standard negative binomial model does not perform as badly as the standard Poisson model, but it still has substantially biased parameter estimates, and its confidence intervals for small values of $E\left(\lambda_{i}\right)$ reject much too often.

In summary, these results suggest that the failure to account for overdispersion in truncated samples of count data can have serious consequences for estimation and inference. The greater the degree of overdispersion, the worse the resulting inconsistencies.

\section{AN EMPIRICAL APPLICATION: FISHING TRIPS}

In this section we illustrate the use of various count data models to estimate the number of fishing trips a household in Alaska takes during the 22 -week Alaskan fishing season. ${ }^{6}$ The

\footnotetext{
${ }^{6}$ The data used in this section come from a series of surveys conducted by Jones and Stokes Associates (1987) for the Alaska Department of Fish and Game.
} 
available sample is from a diary survey of 1063 Alaskan households. To have been included in the sample, a household must have taken at least one fishing trip. The maximum number of fishing trips taken was 67, the mean number of fishing trips taken by Alaska's fishing households was $6 \cdot 43$, the median number of trips 5 , and the standard deviation $6 \cdot 39$ trips. A large number of covariates are available in the data set.

The function we estimate is known as a participation equation in the recreation demand literature. This equation has typically been estimated using ordinary least-squares. The other function typically estimated with micro-data in this literature is known as a site selection equation (Morey, 1981). This function, which predicts where a household will go to recreate conditional on their having decided to make a recreational trip, is now usually estimated using a multinomial or nested logic framework (Smith, forthcoming). Much less attention has been paid to estimating the participation equation than to estimating the site selection equation. ${ }^{7}$

Table II presents parameter estimates from standard and truncated forms of the Poisson and negative binomial models. Given the large number of possible predictor variables available, the specification used should be considered illustrative. ${ }^{8}$ The variables used are: AVLONG, the

Table II. Estimates for seasonal fishing models

\begin{tabular}{|c|c|c|c|c|c|c|}
\hline Variable & OLS & $\begin{array}{c}\mathrm{NLS} \\
Y=\exp (X \beta)\end{array}$ & $\begin{array}{l}\text { Standard } \\
\text { Poisson }\end{array}$ & $\begin{array}{l}\text { Truncated } \\
\text { Poisson }\end{array}$ & $\begin{array}{l}\text { Standard } \\
\text { negative } \\
\text { binomial }\end{array}$ & $\begin{array}{l}\text { Truncated } \\
\text { negative } \\
\text { binomial }\end{array}$ \\
\hline AVLONG & $\begin{array}{l}-1 \cdot 1329 \\
(10 \cdot 06)\end{array}$ & $\begin{array}{c}-0 \cdot 2457 \\
(8 \cdot 63)\end{array}$ & $\begin{array}{l}-0 \cdot 2242 \\
(22 \cdot 44)\end{array}$ & $\begin{array}{l}-0 \cdot 2388 \\
(22 \cdot 34)\end{array}$ & $\begin{array}{l}-0 \cdot 2142 \\
(10 \cdot 93)\end{array}$ & $\begin{array}{c}-0 \cdot 2575 \\
(9 \cdot 90)\end{array}$ \\
\hline MISS & $\begin{array}{c}-0 \cdot 8943 \\
(2 \cdot 09)\end{array}$ & $\begin{array}{c}-0 \cdot 1235 \\
(1 \cdot 80)\end{array}$ & $\begin{array}{c}-0 \cdot 1356 \\
(4 \cdot 62)\end{array}$ & $\begin{array}{c}-0 \cdot 1376 \\
(4 \cdot 62)\end{array}$ & $\begin{array}{c}-0 \cdot 1372 \\
(2 \cdot 52)\end{array}$ & $\begin{array}{c}-0 \cdot 1597 \\
(2 \cdot 26)\end{array}$ \\
\hline CROWD & $\begin{array}{c}-0.4973 \\
(2 \cdot 64)\end{array}$ & $\begin{array}{c}-0 \cdot 0667 \\
(2 \cdot 41)\end{array}$ & $\begin{array}{c}-0 \cdot 0747 \\
(5 \cdot 99)\end{array}$ & $\begin{array}{c}-0 \cdot 0763 \\
(5 \cdot 30)\end{array}$ & $\begin{array}{c}-0 \cdot 0712 \\
(3 \cdot 09)\end{array}$ & $\begin{array}{c}-0.0756 \\
(2 \cdot 64)\end{array}$ \\
\hline INC & $\begin{array}{c}-0 \cdot 0133 \\
(2 \cdot 29)\end{array}$ & $\begin{array}{c}-0 \cdot 0018 \\
(2 \cdot 18)\end{array}$ & $\begin{array}{c}-0 \cdot 0014 \\
(3 \cdot 87)\end{array}$ & $\begin{array}{c}-0 \cdot 0014 \\
(3 \cdot 70)\end{array}$ & $\begin{array}{c}-0 \cdot 0013 \\
(1 \cdot 79)\end{array}$ & $\begin{array}{c}-0 \cdot 0013 \\
(1 \cdot 48)\end{array}$ \\
\hline CPMILE & $\begin{array}{l}17 \cdot 0802 \\
(5 \cdot 75)\end{array}$ & $\begin{array}{l}2 \cdot 5050 \\
(7 \cdot 32)\end{array}$ & $\begin{array}{l}2 \cdot 4028 \\
(13 \cdot 42)\end{array}$ & $\begin{array}{c}2 \cdot 4414 \\
(13 \cdot 53)\end{array}$ & $\begin{array}{l}2 \cdot 3317 \\
(6 \cdot 64)\end{array}$ & $\begin{array}{l}2 \cdot 4136 \\
(5 \cdot 87)\end{array}$ \\
\hline FOFF1 & $\begin{array}{c}-0 \cdot 9267 \\
(4 \cdot 94)\end{array}$ & $\begin{array}{c}-0 \cdot 1806 \\
(5 \cdot 49)\end{array}$ & $\begin{array}{l}-0 \cdot 1630 \\
(12 \cdot 30)\end{array}$ & $\begin{array}{l}-0 \cdot 1694 \\
(12 \cdot 52)\end{array}$ & $\begin{array}{c}-0 \cdot 1570 \\
(7 \cdot 09)\end{array}$ & $\begin{array}{c}-0 \cdot 1882 \\
(6 \cdot 50)\end{array}$ \\
\hline LEISURE & $\begin{array}{l}0 \cdot 5920 \\
(3 \cdot 23)\end{array}$ & $\begin{array}{l}0 \cdot 0841 \\
(3 \cdot 35)\end{array}$ & $\begin{array}{l}0 \cdot 0811 \\
(6 \cdot 90)\end{array}$ & $\begin{array}{l}0 \cdot 0818 \\
(6 \cdot 41)\end{array}$ & $\begin{array}{l}0 \cdot 0782 \\
(3 \cdot 59)\end{array}$ & $\begin{array}{l}0 \cdot 0885 \\
(3 \cdot 06)\end{array}$ \\
\hline TRATE & $\begin{array}{l}4 \cdot 8842 \\
(6 \cdot 77)\end{array}$ & $\begin{array}{l}0 \cdot 8067 \\
(8 \cdot 01)\end{array}$ & $\begin{array}{c}0 \cdot 7051 \\
(15 \cdot 13)\end{array}$ & $\begin{array}{c}0 \cdot 7170 \\
(15 \cdot 17)\end{array}$ & $\begin{array}{l}0 \cdot 6360 \\
(7 \cdot 57)\end{array}$ & $\begin{array}{l}0 \cdot 6324 \\
(6 \cdot 37)\end{array}$ \\
\hline CONST & $\begin{array}{c}-8 \cdot 0664 \\
(3 \cdot 27)\end{array}$ & $\begin{array}{c}-0 \cdot 4786 \\
(1 \cdot 37)\end{array}$ & $\begin{array}{c}-0 \cdot 1788 \\
(1 \cdot 10)\end{array}$ & $\begin{array}{c}-0 \cdot 2027 \\
(1 \cdot 23)\end{array}$ & $\begin{array}{c}0.0291 \\
(0.09) \\
0.4069 \\
(15.96)\end{array}$ & $\begin{array}{c}0.0116 \\
(0 \cdot 11) \\
0.6347 \\
(12 \cdot 96)\end{array}$ \\
\hline $\log L$ & $-3396 \cdot 69$ & $-3378 \cdot 13$ & $-3769 \cdot 00$ & $-3751 \cdot 94$ & $-2929 \cdot 44$ & $-2839 \cdot 75$ \\
\hline
\end{tabular}

Absolute value of $t$-statistic in parentheses.

\footnotetext{
${ }^{7}$ The early recreation demand literature and aggregate data on per capita visits from different areas to a particular recreation site and the average cost of travelling to the site from the different areas to estimate an implied demand for the site as a function of the cost of visiting it. These simple 'travel cost' models lost favour when micro-data sets on household recreation behaviour first started becoming widely available in the mid-1970s. The current state of the art in recreation demand modelling is reviewed in Bockstael, McConnell, and Strand (forthcoming). Unfortunately, most applied work in this area uses fairly primitive techniques unsuited for the statistical properties of the data.

${ }^{8}$ The variables used are those suggested by ordinary regression models and logit models in the recreation demand literature.
} 
average length of recreational fishing trips taken; MISS, a dummy variable which indicates that the last part of the diary survey was not returned; CROWD, a factor score estimated from attitudinal variables on crowding; INC, the household income in thousands of dollars; CPERM, the cost per mile, in cents of operating the vehicle the household uses for fishing trips; FOFF1, a factor score estimated from indicators of preseason familiarity with different fishing sites; LEISURE, a factor score estimated from indicators of the amount of leisure time available and alternative work opportunities; and TRATE, a measure of fishing quality at different sites discounted by the household's distance from them (i.e. the inclusive value from a nested logit model of fishing site/species choice). ${ }^{9}$ Table II also presents parameter estimates from the linear least-squares model (OLS) and from nonlinear least-squares (NLS) model $y=\exp (X \beta)+\varepsilon$ where $\varepsilon$ is considered to be normally distributed. The coefficients from the NLS model are directly comparable to those from the count data models, whereas those from a linear least-squares model are not. The OLS coefficients can best be compared to the other models by looking at the elasticities they imply at different points or at mean elasticities.

Based on the log-likelihood, the truncated negative binomial model fits best $(-2839 \cdot 75)$, followed by the standard negative binomial $(-2929 \cdot 44)$ with the NLS and OLS regression model are a poor third $(-3378 \cdot 13)$ and fourth $(-3396 \cdot 69)$, respectively. The two Poisson models fit dramatically worse. Indeed, they both fit worse than a simple regression model with only a constant term which has a log-likelihood of $-3479 \cdot 63$. This result is due largely to the incorrect imposition of an equality restriction between the mean and variance by the Poisson models. The unconditional variance of the trip variable is over six times that of the mean. Conditioning on the covariates reduces this appaent overdispersion, but not nearly enough to get a mean-variance equality. The other models do not impose this restriction and have one more estimated parameter than the Poisson models. The truncated Poisson fits only marginally better than the standard Poisson model, because with a mean number of trips of $6 \cdot 43$, one would not expect to see many zeros. The Poisson and negative binomial log-likelihood values are very different. The log-likelihood of the truncated negative binomial $(-2839 \cdot 75)$ indicates a significantly better fit than the standard negative binomial $(-2929 \cdot 44)$.

Across all of the models, most of the variables have the expected signs; and the qualitative results are consistent across each of the six models. The number of trips goes down with the length of trips taken, a negative attitude towards crowding, lack of familiarity with different fishing sites, and income. The coefficient on MISS allows one to estimate the number of trips which went unreported due to the failure to return the last portion of the diary survey. The number of trips increases with the amount of leisure time available and the fishing quality discounted by distance. The positive coefficient on CPERM reflects the fact that CPERM is largely an indicator of the presence of capital equipment. Low values of CPERM indicate the use of regular automobiles for fishing trips, middle-range values indicate trucks or vehicles pulling boats, and high values indicate campers, large trailers, or other large recreational vehicles which make in possible to avoid lodging expenses.

A closer examination of the parameter values suggests that they do not vary greatly across the six specifications. To a large extent this should be expected. The mean number of trips is $6 \cdot 43$, large enough that the normal should be a good approximation to the Poisson and none of the estimators should be grossly affected by the truncation at zero trips. This similarity of coefficient estimates is also consistent with our simulation results, which indicated that the Poisson estimates suffered from relatively little bias for mean counts of the magnitude reported

\footnotetext{
${ }^{9}$ The mean value of each of these variables is given in the parentheses: AVLONG $(2 \cdot 47)$, MISS $(0 \cdot 24)$, CROWD $(0)$, INC $(51 \cdot 13)$, CPMILE $(0 \cdot 13)$, FOFF1 $(0)$, LEISURE $(0)$, and TRATE $(3 \cdot 26)$.
} 
here, even in the presence of moderate overdispersion. Differences between the coefficient estimates are most noticeable for TRATE, the policy variable. TRATE can be increased by such actions as stocking fish, reducing the commercial catch, rehabilitating fish spawning areas, opening new fishing sites, or reducing congestion. The NLS model implies an elasticity of 2.63 at the mean TRATE which is 28 per cent larger than that of the truncated negative binomial $(2 \cdot 06)$. The truncated Poisson model implies an elasticity which is 12 per cent larger than the truncated negative binomial. The OLS model's elasticity evaluated at the mean TRATE is 20 per cent larger. These differences may be important for policy decisions based on the responsiveness of the public to potentially costly improvements in fishing quality.

Examination of the $t$-statistics reveals that the estimated standard errors vary considerably across specifications. This finding serves to reinforce one of the conclusions from the MonteCarlo study: failure to account for overdispersion can have very serious consequences for inference, even when the average number of counts is fairly high. Failure to account for the truncation can also result in estimates of coefficient standard errors which are too small, although this effect is less pronounced here due to the large mean number of trips.

The absolute values of the $t$-statistics in the Poisson models are approximately twice those of their negative binomial counterparts. The OLS and NLS $t$-statistics are much closer to those of the negative binomial models, being larger for some parameter estimates and for others smaller. The standard negative binomial model has absolute $t$-values which are on average a little over 10 per cent larger than those of the truncated negative binomial models. In most instances one would draw the same qualitative inference from all of the models.

An important exception arises in the case of the income coefficient, however. The point estimates are negative across all specifications; and this frequent counterintuitive result has been rationalized in the literature as arising from (conjectured) preferences of higher-income persons for other forms of recreation. The OLS and NLS estimates are significant at greater than the 95 per cent confidence level, as are the estimates from both Poisson estimators. The standard negative binomial estimate is only significant at the 90 per cent confidence level, while the estimate from the truncated negative binomial is not significant at any commonly used confidence level.

Interestingly, the effects of overdispersion seem to be much more important here to goodness of fit than is truncation. Again this is due in large part to the fairly large mean number of trips taken. ${ }^{10}$ Creel and Loomis (1990), implementing the estimators proposed in an earlier version of this paper (Grogger and Carson, 1988), looked at deer-hunting trips in California, which has a much smaller mean, $2 \cdot 47$, and found that truncation had a much more pronounced effect than overdispersion. We obtain similar results predicting the number of fishing trips that our respondents take in a shorter time interval (e.g. a particular month) where the mean number of trips taken is, of course, much smaller.

\section{CONCLUDING REMARKS}

Our motivation in developing the truncated count data models presented here was the feeling that there are a large number of potential applications for such models. Currently we are using them to predict the weekly number of recreational fishing trips taken in Alaska and the number of arrests among a population of individuals with at least one arrest. Applications from the fields of transportation and labour economics also seem natural.

\footnotetext{
${ }^{10}$ It is worth cautioning here that what is large for the mean of a Poisson distribution in terms of convergence to a normal is not necessarily large for a negative binomial distribution, particularly one with a sizeable $\alpha$.
} 
A finding which shows up throughout this paper is the great importance of overdispersion in the estimation of the truncated count models. Our Monte-Carlo results showed that regression coefficients can be substantially biased when overdispersion is not accounted for and the mean number of counts is relatively low; that is, when many zeros would be expected in a nontruncated sample. The simulation results and the empirical example pointed out the serious consequences for inference that may arise when overdispersion is neglected, even when mean counts are large. Some of the specification tests of the Poisson versus the negative binomial in the nontruncated case can be easily extended to cover the truncated case. Given that only one tail of the distribution is observable, special attention should be paid to deriving tests with particular power against overdispersion in the upper tail. The finite sample performance of all these tests would need to be assessed. Our experience suggests that the Poisson mean-variance equality restriction is rarely appropriate. ${ }^{11}$

Researchers using the estimators presented should also be aware that modifications are likely to be required for different sampling plans. We have implicitly assumed that a random sample of those agents with positive values of $Y_{i}$ is being used, as will often be the case. In the area of recreation demand the most common examples are the periodic surveys of licence-holders conducted by many states.

We should mention two other common sampling plans in this literature. ${ }^{12}$ The first is a choice-based sampling plan known as on-site sampling (Robson and Jones, 1989; Shaw, 1988) in which the probability of inclusion in the sample is proportionate to the number of visits to the site. Such surveys are often conducted by the US Forest Service and the National Park Service. An on-site sampling plan will often require merely a fairly simple weighting adjustment to the estimators presented. Some designs, particularly those with a capture-recapture structure which collect primarily information about the present trip, may require quite complicated weighting adjustments.

The second is a two-stage or double sampling scheme (Neyman, 1938) in which a large 'screening' survey is administered to a large random sample of all households, with a detailed follow-up survey of only those indicating that they participated in one or more of the activities of interest. The US Fish and Wildlife Service's National Survey of Fishing, Hunting, and Wildlife Related Activities does this explicitly, and many of the National Marine Fisheries telephone surveys do this implicitly by almost immediately terminating interviews with respondents who do not engage in fishing. ${ }^{13}$ This screening presents an interesting dilemma: very few additional questions are asked of households interviewed in the screening survey, which makes the estimation of a selection equation difficult. The situation is further complicated by a mixing of two types of zeros: those who would engage in the recreational activity in question if conditions were right (e.g. fishing quality or leisure time increased) and those who would not engage in the activity under any circumstance. The first type of zeros are sometimes known as stochastic zeros while the second type of zeros are known as structural zeros. If the observed zeros are a mixture of the two types, the researcher may be better off simply using the appropriate truncated count data estimator on the positive counts, as inclusion of a large number of structural zeros will severely bias the regression coefficients for the trip-generation process of interest.

\footnotetext{
${ }^{11}$ We have only seen one economic variable, the number of jobs held by male respondents to the 1980 Wave of the National Longitudinal Survey of Youth, in which the mean-variance equality appears to hold.

${ }^{12}$ These two sampling plans are also frequently used in other areas such as marketing and transportation.

${ }^{13}$ With the few exceptions, e.g. Smith (1990), the empirical work on estimating participation functions from these data sets has not been sensitive to the integer nature of the trip variable or two the two-stage sampling plan used. See Walsh, Johnson and McKean (1988) for an overview of many of the studies based on US Fish and Wildlife Service surveys.
} 
A number of extensions could be made to the models presented. We note two here. The first involves incorporating techniques developed in survival analysis for handling different kinds of unobservable heterogeneity among sample members, particularly heterogeneity which results in self-selection into the observable sample. The second involves extensions of a univariate estimator proposed by Cohen (1960) for the case where some but not all of the zero counts are observed. This extension seems particularly relevant to some panel designs such as the data set used by Hausman, Hall, and Griliches (1984) in which zeros are observed but inclusion into the sample required that a patent be filed in least 1 year. ${ }^{14}$

\section{ACKNOWLEDGEMENTS}

We wish to thank Glenn Sueyoshi, Halbert White, the members of the UC San Diego Econometrics workshop and two anonymous referees for their helpful comments. Any remaining errors are of course our own.

\section{REFERENCES}

Aptech Systems (1989), 'COUNT module reference list', GAUSS Newsletter, 5, 4-6.

Bockstael, N., T. McConnell and I. Strand (forthcoming), 'Recreation', in J. B. Braden and C. D. Kolstad, (eds), Measuring the Demand for Environmental Improvements, North-Holland, Amsterdam.

Cameron, A. C., and P. K. Trivedi (1986), 'Econometric models based on count data: comparisons and application of some estimators and tests', Journal of Applied Econometrics, 1, 29-53.

Cameron, A. C., P. K. Trivedi, F. Milne and J. Piggott (1988), 'A microeconometric model of the demand for health care and health insurance in Australia', Review of Economic Studies, 55, 85-106.

Cohen, A. C. (1954), 'Estimation of the Poisson parameter from truncated samples and from censored samples', Journal of the American Statistical Association, 49, 158-168.

Cohen, A. C. (1960), 'Estimation in the truncated Poisson distribution when the zeros and some ones are missing', Journal of the American Statistical Association, 55, 342-348.

Gragg, J. G. (1971), 'Some statistical models for limited dependent variables with application to the demand for durable goods', Econometrica, 39, 829-844.

Creel, M., and J. Loomis (1990), 'Theoretical and empirical advantages of truncated count data estimators for analysis of deer hunting in California', American Journal of Agricultural Economics, 72, 434-41.

Gourieroux, C., A. Monfort and A. Trognon (1984a), 'Pseudo maximum likelihood methods: theory', Econometrica, 52, 681-700.

Gourieroux, C., A. Monfort and A. Trognon (1984b), 'Pseudo maximum likelihood methods: applications to Poisson models', Econometrica, 52, 701-720.

Greene, W. (1990), LIMDEP Version 5.1, Econometric Software, New York.

Grogger, J. (1987), 'Efficient criminal justice policy and the deterrent effect of capital punishment', unpublished Ph.D. dissertation, University of California, San Diego.

Grogger, J. (1990), 'The deterrent effect of capital punishment: an analysis of daily homicide counts', Journal of the American Statistical Association, 85, 295-303.

Grogger, J., and R. Carson (1988), 'Models for counts from choice-based samples', Discussion paper 88-9, Department of Economics, University of California, San Diego.

Hausman, J., B. Hall and Z. Griliches (1984), 'Econometric models for count data with an application to the patents-R\&D relationship', Econometrica, 52, 909-938.

Hinde, J. (1982), 'Compound Poisson models', in R. Gilchrist, (ed.), GLIM82: Proceedings of the International Conference on Generalized Linear Models, Sringer-Verlag, New York.

\footnotetext{
${ }^{14}$ This extension is also relevant to estimation of the participation function from the National Marine Fisheries (or Fish and Wildlife Service) surveys, particularly for very specific recreation activities such a halibut fishing as opposed to say, just marine fishing. In this case the researcher will have detailed information on some of the zeros, i.e. those marine fishing but not halibut fishing, but not all of the zeros, i.e. those not marine fishing.
} 
Johnson, N. L., and S. Kotz (1969), Discrete Distributions, Wiley, New York.

Jones and Stokes Associates (1987), 'Southcentral Alaska area sport fishing study', a report to the Alaska Department of Fish and Game.

Lee, L. F. (1986), 'Specification tests for Poisson regression models', International Economic Review, 27, 689-706.

McCullagh, P. (1983), 'Quasi-likelihood functions', Annals of Statistics, 11, 59-67.

McDonald, J., and R. Moffitt (1980), 'The uses of Tobit analysis', Review of Economics and Statistics, 62, 318-321.

Morey, E. R. (1981), 'The demand for site specific recreational activities: a characteristic approach', Journal of Environmental Economics and Management, 8, 345-371.

Mullahy, J. (1986), 'Specification and testing of some modified count data models', Journal of Econometrics, 33, 341-365.

Neyman, J. (1938), 'Contributions to the theory of sampling human populations', Journal of the American Statistical Association, 33, 101-116.

Portney, P. R., and J. Mullahy (1986), 'Urban air quality and acute respiratory illness', Journal of Urban Economics, 20, 21-38.

Robson, D. and C. M. Jones (1989), 'Theoretical basis of an access site angler survey design', Biometrics, 45, 83-98.

Shaw, D. (1988), 'On-site samples' regression problems of non-negative integers, truncation, and endogenous stratification', Journal of Econometrics, 37, 211-223.

Smith, V. K. (1990), 'Selection and recreation demand', American Journal of Agricultural Economics, 70, 29-36.

Smith, V. K. (forthcoming), 'Household production functions', in J. B. Braden, and C. D. Kolstad, (eds), Measuring the Demand for Environmental Improvements, North-Holland, Amsterdam.

Walsh, R. G., D. M. Johnson and J. R. McKean (1988), 'Review of outdoor research economic demand studies with non-market benefit estimates: 1968-1988', Technical Report No. 54, Colorado Water Resources Research Institute, Colorado State University.

Wedderburn, R. W. M. (1974), 'Quasi-likelihood functions, generalized linear models and the Gauss-Newton method', Biometrika, 61, 439-447. 
http://www.jstor.org

\title{
LINKED CITATIONS
}

\author{
- Page 1 of 4 -
}

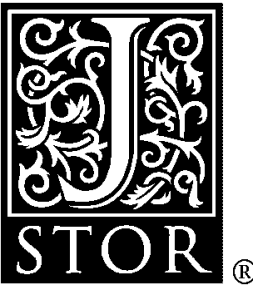

You have printed the following article:

\section{Models for Truncated Counts}

J. T. Grogger; R. T. Carson

Journal of Applied Econometrics, Vol. 6, No. 3. (Jul. - Sep., 1991), pp. 225-238.

Stable URL:

http://links.jstor.org/sici?sici=0883-7252\%28199107\%2F09\%296\%3A3\%3C225\%3AMFTC\%3E2.0.CO\%3B2-N

This article references the following linked citations. If you are trying to access articles from an off-campus location, you may be required to first logon via your library web site to access JSTOR. Please visit your library's website or contact a librarian to learn about options for remote access to JSTOR.

\section{[Footnotes]}

\author{
${ }^{13}$ Selection and Recreation Demand \\ V. Kerry Smith \\ American Journal of Agricultural Economics, Vol. 70, No. 1. (Feb., 1988), pp. 29-36. \\ Stable URL: \\ http://links.jstor.org/sici?sici=0002-9092\%28198802\%2970\%3A1\%3C29\%3ASARD\%3E2.0.CO\%3B2-S
}

\section{References}

Econometric Models Based on Count Data: Comparisons and Applications of Some Estimators and Tests

A. Colin Cameron; Pravin K. Trivedi

Journal of Applied Econometrics, Vol. 1, No. 1. (Jan., 1986), pp. 29-53.

Stable URL:

http://links.jstor.org/sici?sici=0883-7252\%28198601\%291\%3A1\%3C29\%3AEMBOCD\%3E2.0.CO\%3B2-M

\author{
A Microeconometric Model of the Demand for Health Care and Health Insurance in Australia \\ A. C. Cameron; P. K. Trivedi; Frank Milne; J. Piggott \\ The Review of Economic Studies, Vol. 55, No. 1. (Jan., 1988), pp. 85-106. \\ Stable URL: \\ http://links.jstor.org/sici?sici=0034-6527\%28198801\%2955\%3A1\%3C85\%3AAMMOTD\%3E2.0.CO\%3B2-5
}

NOTE: The reference numbering from the original has been maintained in this citation list. 
http://www.jstor.org

\section{LINKED CITATIONS}

- Page 2 of 4 -

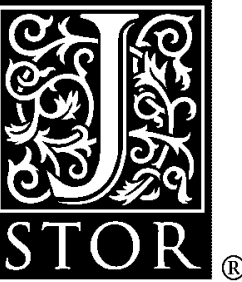

Estimation of the Poisson Parameter from Truncated Samples and from Consored Samples A. C. Cohen, Jr. Journal of the American Statistical Association, Vol. 49, No. 265. (Mar., 1954), pp. 158-168. Stable URL: http://links.jstor.org/sici?sici=0162-1459\%28195403\%2949\%3A265\%3C158\%3AEOTPPF\%3E2.0.CO\%3B2-6

Estimation in the Truncated Poisson Distribution when Zeros and Some Ones are Missing A. Clifford Cohen, Jr.

Journal of the American Statistical Association, Vol. 55, No. 290. (Jun., 1960), pp. 342-348.

Stable URL:

http://links.jstor.org/sici?sici=0162-1459\%28196006\%2955\%3A290\%3C342\%3AEITTPD\%3E2.0.CO\%3B2-O

Theoretical and Empirical Advantages of Truncated Count Data Estimators for Analysis of Deer Hunting in California

Michael D. Creel; John B. Loomis

American Journal of Agricultural Economics, Vol. 72, No. 2. (May, 1990), pp. 434-441.

Stable URL:

http://links.jstor.org/sici?sici=0002-9092\%28199005\%2972\%3A2\%3C434\%3ATAEAOT\%3E2.0.CO\%3B2-T

\section{Pseudo Maximum Likelihood Methods: Theory}

C. Gourieroux; A. Monfort; A. Trognon

Econometrica, Vol. 52, No. 3. (May, 1984), pp. 681-700.

Stable URL:

http://links.jstor.org/sici?sici=0012-9682\%28198405\%2952\%3A3\%3C681\%3APMLMT\%3E2.0.CO\%3B2-N

\section{Pseudo Maximum Likelihood Methods: Applications to Poisson Models}

C. Gourieroux; A. Monfort; A. Trognon

Econometrica, Vol. 52, No. 3. (May, 1984), pp. 701-720.

Stable URL:

http://links.jstor.org/sici?sici=0012-9682\%28198405\%2952\%3A3\%3C701\%3APMLMAT\%3E2.0.CO\%3B2-4

The Deterrent Effect of Capital Punishment: An Analysis of Daily Homicide Counts Jeffrey Grogger

Journal of the American Statistical Association, Vol. 85, No. 410. (Jun., 1990), pp. 295-303. Stable URL:

http://links.jstor.org/sici?sici=0162-1459\%28199006\%2985\%3A410\%3C295\%3ATDEOCP\%3E2.0.CO\%3B2-O

NOTE: The reference numbering from the original has been maintained in this citation list. 
http://www.jstor.org

\title{
LINKED CITATIONS
}

\author{
- Page 3 of 4 -
}

Econometric Models for Count Data with an Application to the Patents-R \& D Relationship

Jerry Hausman; Bronwyn H. Hall; Zvi Griliches

Econometrica, Vol. 52, No. 4. (Jul., 1984), pp. 909-938.

Stable URL:

http://links.jstor.org/sici?sici=0012-9682\%28198407\%2952\%3A4\%3C909\%3AEMFCDW\%3E2.0.CO\%3B2-M

\section{Specification Test for Poisson Regression Models}

Lung-Fei Lee

International Economic Review, Vol. 27, No. 3. (Oct., 1986), pp. 689-706.

Stable URL:

http://links.jstor.org/sici?sici=0020-6598\%28198610\%2927\%3A3\%3C689\%3ASTFPRM\%3E2.0.CO\%3B2-5

\section{Quasi-Likelihood Functions}

Peter McCullagh

The Annals of Statistics, Vol. 11, No. 1. (Mar., 1983), pp. 59-67.

Stable URL:

http://links.jstor.org/sici?sici=0090-5364\%28198303\%2911\%3A1\%3C59\%3AQF\%3E2.0.CO\%3B2-9

\section{The Uses of Tobit Analysis}

John F. McDonald; Robert A. Moffitt

The Review of Economics and Statistics, Vol. 62, No. 2. (May, 1980), pp. 318-321.

Stable URL:

http://links.jstor.org/sici?sici=0034-6535\%28198005\%2962\%3A2\%3C318\%3ATUOTA\%3E2.0.CO\%3B2-2

\section{Contribution to the Theory of Sampling Human Populations}

J. Neyman

Journal of the American Statistical Association, Vol. 33, No. 201. (Mar., 1938), pp. 101-116.

Stable URL:

http://links.jstor.org/sici?sici=0162-1459\%28193803\%2933\%3A201\%3C101\%3ACTTTOS\%3E2.0.CO\%3B2-N

\section{The Theoretical Basis of an Access Site Angler Survey Design}

Douglas Robson; Cynthia M. Jones

Biometrics, Vol. 45, No. 1. (Mar., 1989), pp. 83-98.

Stable URL:

http://links.jstor.org/sici?sici=0006-341X\%28198903\%2945\%3A1\%3C83\%3ATTBOAA\%3E2.0.CO\%3B2-E

NOTE: The reference numbering from the original has been maintained in this citation list. 
http://www.jstor.org

\section{LINKED CITATIONS \\ - Page 4 of 4 -}

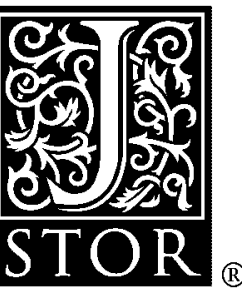

\section{Selection and Recreation Demand}

V. Kerry Smith

American Journal of Agricultural Economics, Vol. 70, No. 1. (Feb., 1988), pp. 29-36.

Stable URL:

http://links.jstor.org/sici?sici=0002-9092\%28198802\%2970\%3A1\%3C29\%3ASARD\%3E2.0.CO\%3B2-S

Quasi-Likelihood Functions, Generalized Linear Models, and the Gauss-Newton Method R. W. M. Wedderburn

Biometrika, Vol. 61, No. 3. (Dec., 1974), pp. 439-447.

Stable URL:

http://links.jstor.org/sici?sici=0006-3444\%28197412\%2961\%3A3\%3C439\%3AQFGLMA\%3E2.0.CO\%3B2-F

NOTE: The reference numbering from the original has been maintained in this citation list. 